Vol 1, No. 2 (2020), Desember 2020

E-ISSN: 2746-2471, DOI:

\title{
KINERJA AKTIVITAS PEMASARAN PADA USAHA MIKRO KEDAI SUSU SEGAR WR. AGUS
}

\author{
Ayu Rahmawati ${ }^{1)}$, Endah Widati ${ }^{2)}$ \\ Fakultas llmu Pendidikan dan Pengetahuan Sosial \\ ${ }^{12}$ Universitas Indraprasta PGRI \\ Ayurahmawati674@yahoo.co.id,endahwidati82@gmail.com
}

Dikirim:11Desember 2020 Direvisi:31 Desember 2020 Dipublikasikan: 31 Desember 2020

\begin{abstract}
ABSTRAK
Selama didirikan usaha mikro Kedai Susu Segar Wr. Agus mengalami masa baik peningkatan yang tidak terlalu signifikan serta kecenderungan penurunan penjuala dalam beberapa bulan terakhir selama tahun 2020. Hal ini tentu bukan merupakan sesuatu yang baik bagi pihak pemilik Kedai susu segar sendiri. Dan jika dibiarkan terusmenerus mungkin Kedai susu tidak dapat mempertahankan eksitensi dan kalah dalam persaingan ditengah banyaknya pelaku bisnis sejenis yang bermunculan dan saling bersaingPenelitianini bertujuan untuk mengetahui apakah aktivitas pemasaran yang dilakukan oleh usah amikro Kedai Susu Segar Wr. Agus sudah tepat dalam menghadapi pesaing dan meningkatkan volume penjualan. Metode penelitian yang digunakan adalah evaluasi kualitatif deskriptif, dengan menggunakan teknik analisis data berupa Analisis VRIO, Analisis PESTL, Analisis Pesaing dan Analisis Profitabilitas. Berdasarkan hasil penelitian didapat bahwa aktivitas pemasaran yang dilakukan oleh usaha mikro Kedai Susu Segar Wr. Agus sudah efektif untuk Cabang 1 tetapi untuk Cabang 2 belum efektif karena target penjualan masih belum bisa membuat usaha ini mencapai skala ekonomis.
\end{abstract}

Kata Kunci: Pemasaran, Aktivitas Pemasaran, Kinerja Pemasaran, Analisis Lingkungan, Analisis Profitabilitas

\section{A. PENDAhuluan}

Perkembangan industri susu dalam usaha akan mendorong peningkatan industri persusuan untuk memenuhi kebutuhan internasional maupun dalam negeri. Industri susu juga dapat menciptakan iklim investasi yang baik melalui kemitraan yang saling menguntungkan antara perusahaan dengan peternak. Bentuk kemitraan tersebut dapat berupa pemanfaatan susu segar dalam negeri 
Vol 1, No. 2 (2020), Desember 2020

E-ISSN: 2746-2471, DOI:

(SSDN), penyediaan sarana produksi, peningkatan produktivitas susu, permodalan atau pembiayaan, dan promosi dengan prinsip saling memerlukan, mempercayai, memperkuat dan menguntungkan.

Dalam perkembangan industri susu segar internasional mengalami penurunan, terbukti berdasarkan data BPS tahun 2018. Tingkat Konsumsi susu masyarakat masih rendah bahkan menurun, terlihatdari data konsumsi susu segarintenasionaltahun 2018 antara lain Indonesia 15,98 liter, Malaysia 50,9 liter, Singaura 46,1 liter dan Vietnam 20,1 literterlihat bahwa Indonesia dalam perkembangan konsumsi pertahunnya lebih sedikit dibandingkan dengan Negara lain, hal ini menunjukan bahwa masih banyak diperlukan strategi yang baik bagi setiap pihak yang terlibat dalam industri susu dalam upaya peningkatan konsumsi susu.

Sekarang ini banyak pelaku bisnis di berbagaikategoriusahabaikmikro, kecil dan menengah dan besaryang memilih usaha yang menjual berbagai macam jenis minuman, salah satu usaha tersebut adalah Kedai Susu Segar Wr. Agusyang merupakanusahamikro dan baru memiliki dua cabang, cabang pertama beralamat di Jl. Rawa Dollar Jatisampurna Kota Bekasi di depan Kampus Mercubuana gedung baru Kranggan dan cabang yang kedua beralamat diJl. Ciracas depan Pasar ciracas. Kedai susu ini baru berjalan selama satu tahun dan dapat dikatakan kedai susu ini belum cukup terkenal, tetapi pemilik usaha kedai susu berusaha untuk selalu dapat menciptakan keunggulan kualitas dari produk susu yang dijualnya, selain itu pemilik berusaha untuk selalu meningkatkan kepuasan konsumen melalui berbagaicara yang mampu menunjang usahanya. Ditengah persaingan yang semakin ketat di antara pelaku bisnis sejenis ini memungkinkan adanya perjuangan yang keras dalam mempertahankan usahanya.

Selama didirikan usaha mikro Kedai Susu Segar Wr. Agus mengalami masa baik peningkatan yang tidak terlalu signifikan dan kecenderungan penurunan penjualan dalam beberapa bulan terakhir selama tahun 2020. Hal ini tentu bukan merupakan sesuatu yang baik bagi pihak pemilik Kedai susu segar sendiri. Dan jika dibiarkan terusmenerus mungkin Kedai susu tidak dapat mempertahankan eksitensi dan kalah dalam persaingan ditengah banyaknya pelaku bisnis sejenis yang bermunculan dan saling bersaing. Kedai Susu Segar Wr. Agus harus melakukan berbagaiaktivitas dan strategipemasaran yang lebih baik lagi agar mampu bersaing dan mampu mempertahankan bisnisnya.

\section{B. KAJIAN PUSTAKA}

Kegiatan pemasaran merupakan kegiatan inti suatu usaha/ bisnis, sehingga setiap keputusan yang diambil dalam aspek pemasaran menjadi penentu usaha dimasa yang akan datang.(Khoerunisa, 2019;Kusumawaty, 2018;Pertiwi, 2019). Kotler \& Keller (2016) menjelaskan bahwa pemasarana dalahh aktifitas terkait memenuhi kebutuhan manusia dan lingkungan. Sedangkan American Marketing Association (Kotler \& Keller, 2016) secara formal mendefinisikan kegiatan pemasaran sebagai aktivitas dan proses menciptakan, mengkomunikasikan, menghantarkan dan pertukaran penawaran yang memiliki nilai untuk konsumen, 


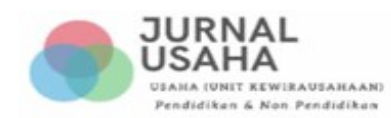

Vol 1, No. 2 (2020), Desember 2020

E-ISSN: 2746-2471, DOI:

klien, mitrakerja, dan masyarakat luas. Adapun aktifitas pemasaran tercakup pada 5 (lima) kegiatan pemasaran(Kotler \& Armstrong, 2017) yaitu (1) memahami pasar dan kebutuhan serta keinginan konsumen; (2) merancang suatu strategi pemasaran berdasarkan nilai konsumen; (3) membuat program pemasaran yang menghantarkan nilai yang superior; (4) mengikat konsumen, membangung hubungan yang profitable dan menciptakan kesenangan konsumen; (5) menangkap nilai konsumen untuk menciptatakan keuntungan dan ekuitas konsumen.

Seperti dijelaskan bahwa salah satu dari aktivitas pemasaran adalah merancang strategi pemasaran berdasarkan nilai konsumen maka perlu dipahami apa itu strategi pemasaran dan proses yang terdapat didalamnya. Strategy pemasaran didefinisikan sebagai rencana yang menjabarkan ekspetasi bisnis akan dampak dari berbagai aktivitas atau program pemasaran terhadap permintaan produk atau lini produknya di pasar sasaran tertentu(Tjiptono \& Chandra, 2017). Sedangkan Assauri(2018) menyatakan bahwa strategi pemasaran sebagai rencana yang menyeluruh, terpadu dan menyatu dibidang pemasaran, yang memberikan panduan tentang kegiatan yang akan dijalankan untuk dapat tercapainya tujuan pemasaran suatu usaha. Dengan kata lain, strategi pemasaran adalah serangkaian tujuan dan sasaran pemasaran serta kebijakan dan aturan yang memberi arah kepada usaha-usaha pemasaran suatubisnis dari waktu kewaktu, pada masingmasing tingkatan dan acuan serta alokasinya, terutama sebagai tanggapan perusahaan dalam menghadapi lingkungan dan keadaan persaingan yang selalu berubah.Sehingga dapat disimpulkan bahwa strategi pemasaran adalahrencana yang menyeluruh dan terpadu mengenai pemasaran yang dijadikan pedoman untuk merencanakan sebuah usaha.

Sedangkan untuk proses strategi pemasaran, Cravens \& Piercy (2012)menyatakan bahwa terdapat empat proses dalam strategi pemasaran yaitu: Pasar, egmentasi dan nilai pelanggan, merancang strategi pasar, pengembangan program strategi pemasaran, melaksanakan dan mengelola strategi pasar.Adapun bauran atau elemen strategi pemasaran menurut McCarthy dalam (Kotler \& Keller, 2016)terdiri dari empat variabel yaitu 4P(Product, Price, Promotion, Place). Sementara itu menurut Booms dan Bitner(1981 dikutip padaArif, 2016) menjelaskan bahwa untuk perusahaan jasa terdapat 3P tambahan yaitu Process, People, Physical Evidence yang jika dijadikan satu menjadi 7P, namun Wirtz \& Lovelock (2016) menambahkan 1 elemen penting sehingga bauran pemasaran menjadi 8P. 1P tersebut yaitu Productivity and Quality. Untuk memastikan setiap aktivitas pemasaran dapat sukses harus diketahui kunci sukses pemasaran sebagai tolak ukur kinerja pemasaran. Adapun kunci sukses aktivitas dan strategi pemasaran menurut Tjiptono \& Chandra (2017)yaitu: kepuasan pelanggan, kualitas layanan dan loyalitas pelanggan.

Setiap aktivitas pemasaran perlu dievaluasi dan diukur, (Kotler \& Keller, 2016)menjelaskan bahwa untuk mengukur kinerja pemasaran menggunakan matrik pemasaran. Matrik pemasaran adalah serangkaian tindakan yang dapat membantu pemasar untuk mengukur, membandingkan, dan menafsirkan kinerja kerja dalam perusahaan. (Kotler \& Keller, 2016). Sedangkan untuk evaluasi 


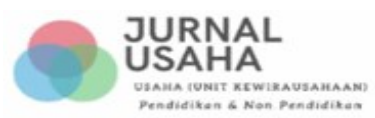

Vol 1, No. 2 (2020), Desember 2020

E-ISSN: 2746-2471, DOI:

strategi pemasaran dapat diukur melalui alat ukur matriks dari beberapa aspek dan matriks yaitu aspek share of hearts, minds and market, margin dan laba, manajemen produk dan portofolio dan profitabilitas pelanggan(Tjiptono \& Chandra, 2017)

\section{METODE PENELITIAN}

Penelitian ini menggunakan metode analisis evaluasi kualitatif deskriptif melalui observasi dan wawancara dengan pemilik dan pengelola usaha mikro Kedai Susu Segar Wr. Agus sebagai sumber data primer penelitian dan berbagai dokumentasi baik berupa tulisan maupun foto-foto. Adapun teknik analisis yang digunakan adalah analisis VRIO (Barney, 1991) dan PESTL untuk menganalisis lingkungan usaha mikro Wr. Susu Agus, analisis pesaing(Porter, 1980) digunakan untuk mengetahui profil pesaing dan analisis profitabilitas(Tjiptono \& Chandra, 2017)untuk menilai kinerja pemasaran selama usaha ini didirikan.

\section{HASIL DAN PEMBAHASAN}

1. Kebijakan dan AktivitasPemasaran

Usaha mikro Kedai Susu Segar Wr. Agus merupakan usaha yang menawarkan produk berupa minuman susu dengan berbagai varian rasa untuk multi pasar di segala umur mulai dari 6 tahun baik perempuan dan laki-laki, baik muda maupun tua. Untuk pasar sasaran (target market), usaha mikroKedai Susu Segar Wr. Agus menargetkan untuk masyarakat yang memilik penghasilan minimal 3,5 juta per bulan atau pelajar dan mahasiswa dengan uang saku minimal Rp. 25,000 per hari. Adapun value positioning yang ingin dibentuk adalah nikmatnya susu murni dengan berbagai varian rasa dengan kualitas terjamin. Usaha mikro Kedai Susu Segar Wr. Agus menawarkan 21variasi rasa susu dengan kisaran harga Rp. 10,000 - Rp. 15,000 (penerapan harga berbeda untuk pembelian langsung dan melalui aplikasi pihak ketiga seperti ojek online) untuk setiap gelas ukuran22 oz atau $650 \mathrm{ml}$. Untuk bisa menikmati susu dariWr. Susu Agus, konsumen dapat mengunjungi stan penjualan yang berlokasi di J1. Rawa Dollar Jatisampurna Kota Bekasi di depan Kampus Mercubuana gedung baru Kranggan dan Jl. Ciracas depan Pasar ciracas. Selain itu, konsumen juga dapat mengunakan aplikasi gofood dan grabfood untuk memesan produk dari Kedai Susu Segar Wr. Agus.

Sedangkan kegiatan komunikasi pemasarannya hanya dilakukan dengan menggunakan spanduk dan juga testimoni (WoM) dari konsumen. Untuk jam operasional, Kedai Susu Segar Wr. Agus mulai berjualan dari jam 09:00 - 20:00 senin-minggu. Adapun jumlah personel untuk menjalankan usaha ini ada 2 yaitu pemilik dan juga karyawan dengan latar belakang pendidikan dan pengalaman yang memadai. Adapun bukti fisik dari usaha ini adalah dan nyata pengenal berupa logo usaha yang ditempel pada paper cup dan gerobak kedai. Sedangkan untuk mengukur produktivitas usaha, pemilik memberikan target penjualan per hari untuk 1 cabangs ebanyak 30 cup dan untuk kualitas produk, pemilik 
Vol 1, No. 2 (2020), Desember 2020

E-ISSN: 2746-2471, DOI:

menggunakan standarisasi umum karena bahan baku yang digunakan adalah bahan baku dengan merek yang jelas dan telah terjamin kualitas serta rasanya berdasarkan institusi yang memberikan izin edar. Berdasarkan hasil observasi menujukkan bahwa rasa yang ditawarkan oleh Kedai Susu Segar Wr. Agus memiliki nilai 4.5 dariskala 5 oleh pengguna aplikasi ojek online dimana Kedai Susu Segar Wr. Agus terdaftar sebagai mitra.

\section{Analisis VRIO}

Analisis VRIO merupakan alat ukur untuk mengukur sumberdaya yang dimiliki oleh internal organisasi, baik usaha mikro, kecil, menengah dan besar sepeti aspek keuangan, asset tetap, kemampuan organisasi, lokasi geografis, produk yang dimiliki oleh usaha mikro Kedai susu segar Wr. Agus selama beroperasi. Untuk menilai setiap sumberdaya dan kapabilitas (kemampuan) diajukan total 17 pertanyaan(Widati, 2012). Adapun hasil penilaian dapa tdilihat pada tabel 1.

\section{Tabel 1}

Interprestasi Hasil AnalisisVrio

\begin{tabular}{|c|c|c|c|c|c|c|c|}
\hline No. & $\begin{array}{c}\text { Kapabilititas } \\
\text { dan sumber } \\
\text { daya }\end{array}$ & Valuable? & Rarity & $\begin{array}{l}\text { Coastly } \\
\text { to } \\
\text { Imitate }\end{array}$ & Organize? & $\begin{array}{l}\text { Implikasi } \\
\text { kompetitif }\end{array}$ & $\begin{array}{l}\text { Kinerja } \\
\text { ekonomis }\end{array}$ \\
\hline 1. & Keuangan & $\mathrm{Ya}$ & Tidak & Tidak & $\mathrm{Ya}$ & $\begin{array}{c}\text { Keunggulan } \\
\text { kompetitif } \\
\text { sementara }\end{array}$ & $\begin{array}{l}\text { Di Atas } \\
\text { Normal }\end{array}$ \\
\hline 2. & Aset Tetap & $\mathrm{Ya}$ & Tidak & Tidak & Tidak & $\begin{array}{c}\text { Keunggulan } \\
\text { Kompetitif } \\
\text { seimbang }\end{array}$ & Normal \\
\hline 3. & Loyalitas Merek & $\mathrm{Ya}$ & Tidak & Tidak & $\mathrm{Ya}$ & $\begin{array}{c}\text { Keunggulan } \\
\text { kompetitif } \\
\text { sementara }\end{array}$ & $\begin{array}{l}\text { Di Atas } \\
\text { Normal }\end{array}$ \\
\hline 4. & $\begin{array}{l}\text { Sumber Daya } \\
\text { Manusia }\end{array}$ & $\mathrm{Ya}$ & Tidak & Tidak & Tidak & $\begin{array}{c}\text { Keunggulan } \\
\text { kompetitif } \\
\text { seimbang }\end{array}$ & Normal \\
\hline 5. & $\begin{array}{l}\text { Kontrak dan } \\
\text { Hubungan }\end{array}$ & $\mathrm{Ya}$ & Tidak & Tidak & $\mathrm{Ya}$ & $\begin{array}{c}\text { Keunggulan } \\
\text { kompetitif } \\
\text { sementara }\end{array}$ & $\begin{array}{l}\text { Di Atas } \\
\text { Normal }\end{array}$ \\
\hline 6 & $\begin{array}{l}\text { kemampuan } \\
\text { Organisasi }\end{array}$ & $\mathrm{Ya}$ & Tidak & Tidak & $\mathrm{Ya}$ & $\begin{array}{c}\text { Keunggulan } \\
\text { kompetitif } \\
\text { sementara }\end{array}$ & $\begin{array}{l}\text { Di Atas } \\
\text { Normal }\end{array}$ \\
\hline 7 & $\begin{array}{l}\text { Pembelajaran } \\
\text { (kemampuan } \\
\text { know-how) }\end{array}$ & $\mathrm{Ya}$ & Tidak & Tidak & $\mathrm{Ya}$ & $\begin{array}{c}\text { Keunggulan } \\
\text { kompetitif } \\
\text { sementara }\end{array}$ & $\begin{array}{l}\text { Di Atas } \\
\text { Normal }\end{array}$ \\
\hline 8. & Jaringan Luar & $\mathrm{Ya}$ & Tidak & Tidak & Tidak & $\begin{array}{c}\text { Keunggulan } \\
\text { kompetitif } \\
\text { seimbang }\end{array}$ & Normal \\
\hline 9. & $\begin{array}{l}\text { Lokasi } \\
\text { Geografis }\end{array}$ & $\mathrm{Ya}$ & Tidak & Tidak & Tidak & $\begin{array}{c}\text { Keunggulan } \\
\text { kompetitif } \\
\text { seimbang }\end{array}$ & Normal \\
\hline 10. & Berinovasi & $\mathrm{Ya}$ & Tidak & Tidak & $\mathrm{Ya}$ & $\begin{array}{c}\text { Keunggulan } \\
\text { kompetitif } \\
\text { sementara }\end{array}$ & $\begin{array}{l}\text { Di Atas } \\
\text { Normal }\end{array}$ \\
\hline
\end{tabular}

Sumber : data diolah (2020) 
Vol 1, No. 2 (2020), Desember 2020

E-ISSN: 2746-2471, DOI:

\section{a. Keuangan}

Dilihat dari segi keuangan pada Kedai susu segar Wr. Agus bahwa sumber modal atau kemampuan yang dimiliki dapat memberikan kesempatan. Meskipun ada beberapa usaha yang sejenis yang hampir sama disekitarnya. Kedai susu segar Wr. Agus dapat mengelola sumber modal dan kemampuan keuangan dengan maksimal sampai sekarang. Hal ini terbukti dengan dibukanya cabang ke2 diawal tahun 2020 dengan modal sepenuhnya dari hasil usaha di cabang pertama

\section{b. Aset tetap}

Dilihat dari segi asset tetap yang dimiliki oleh Kedai susu segar Wr. Agus hanya memiliki motor dan gerobak booth.Pemilik Kedai susu segar Wr. Agus sudah mampu mengelola dan mengembangkan asset tetapd enganbaik, setiap peralatan di rawat dengan baik seperti asset tetap perlengkapan yaitu motor yang digunakan untuk mengambil pesanan dan membeli perlengkapan bahan baku lainnya.Namun asset tetap yang miliki belum dapat memberikan implikasi ekonomi maksimal karena masih dapatdimiliki oleh pesaing.

\section{c. Loyalitas Merek}

Dilihat dari segi loyalitas merek yang dimiliki oleh Kedai susu segar Wr. Agus belum mempunyai nama merek yang cukup terkenal dibandingkan dengan usaha minuman frenchise lainnya sehingga belum memberikan hasil ekonomi maksimal akan tetapi Kedai susu segarWr. Agus mampu bersaing dengan kualitas yang dimiliki pada produknya membuat konsumen merasa puas dan tertarik membelinya kembali.

\section{d. Sumber daya manusia}

Dilihat dari sumber daya manusia yang dimiliki oleh Kedai susu segarWr. Agus sudah mampu mengelolanya dengan baik, pemilik melakukan beberapa seleksi merekrut karyawan yang memiliki pengetahuan, kemampuan karyawan dalam membuat susu dan melayani konsumen dengan baik serta ramah dimana hal ini menjadikan sumberdaya yang dimiliki oleh Kedai Susu Segar Wr. Agus tidak dapat diikuti oleh pesaingdenganmudahkarenaberkaitandengankarakter dan kepribadianmanusia.

\section{e. Kontrak dan Hubungan}

Kedai susu segar Wr. Agus merupakan usaha yang menyediakan minuman selingan yang dibutuhkan untuk konsumen. Dilihat dari kontrak dan hubungan yang dimiliki oleh Kedai susu segar Wr. Agus sudah sangat baik dengan memilih peternak yang terjamin kualitasnya.Hubungan ini sudah terjalin dari awal bisnis dibuka dimana hal ini menjamin untuk Kedai Susu Segar Wr. Agus mendapat pasokan susu segar setiap hari setidaknya 20 liter atau 140 liter seminggu. Selainitu, Kedai susu segar Wr. Agus juga bekerjasama dengan ojek online yaitu Grab dan GoJek untuk memudahkan konsumen mendapat produk Kedai susu segar Wr. Agus. 


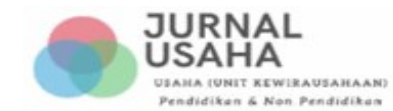

Vol 1, No. 2 (2020), Desember 2020

E-ISSN: 2746-2471, DOI:

Dari hasil kontrak kerjasama dan hubungan ini Kedai susu segar Wr. Agus merasakan implikasi ekonomis berupa penghasilan diatas normal.

\section{f. Kemampuan Organisasi}

Dilihat dari Kemampuan organisasi yang dimiliki Kedai susu segar Wr. Agus sudah mampu karena pemilik Kedai susu segar Wr. Agus dan karyawan dapat bekerja sama dengan baik, dengan dengan beberapa komitmen yang diterapkannya yaitu disiplin dalam waktu, bertanggung jawab dan memberi kepercayaan.NamunsecarastrukturalkemampuanorganisasiKedai Susu Segar Wr. Agusmasihumumdapatdimiliki pesaingsehinggaimplikasiekonomisbelummaksimal

oleh

\section{g. Kemampuan Know-how}

Dilihat dari kemampuan Know-how pemilik Kedai susu segar Wr. Agus sangat menyadari kemampuan yang harus dimiliki sangat berpengaruh besar dengan aktivitaspemasaran Kedai susu. Kemampuan yang dimiliki pada Kedai Susu Segar Wr.Agus yaitu menciptakan varian rasa baru dengan menawarkan kepada konsumen mengenai rasa baru yang ditawarkan Kedai susu segar Wr. Agussehinggahalinimemberikanpenghasilandiatas normal.

\section{h. Jaringan Luar}

Jaringan luar adalah suatu kegiatan yang dilakukan perusahaan atau organisasi untuk menjalin kerja sama dalam membangun usahanya untuk bekerjasama dengan perusahaan lainnya, saat ini Kedai susu segar Wr. Agus sedang bekerja sama dengan Warung Kopi Ciracas yang menjual berbagai jenis minuman kopi, susu dan aneka makanan ringan maupun berat.

\section{i. LokasiGeografis}

Kedai susu segar Wr. Agus tempat lokasinya berada di depan kampus, perumahan, dan jalan utama di jatisampurna bekasi, dan cabang kedua di jalan ciracas depan pasar ciracas. Dilihat dari letak tempat lokasi banyak usaha yang sama dan dekat usaha Kedai susu segar Wr. Agus.

\section{g. Berinovasi}

Inovasi yang dilakukan pada Kedai susu segar Wr. Agus yaitu melakukan penyajiaan rasa baru dengan inovasi lain contohnya saja rasa coklat dicampur dengan rasa vanila hingga rasa yg tersebut menjadi susu rasa coklat es krim. Pesaing tentu saja memiliki kemampuan inovasi yang sama, namun tentunya pesaing memiliki ide yang berbeda.

\section{Analisis PESTL}

\section{a. Ekonomi}

Berdasarkan hasil wawancara pada pemilik Kedai susu segar Wr. Agus di lihat dari aspek ekonomi adanya perubahan harga bahan baku yang digunakan yaitu bubuk perasa dan sirup serta kemampuan daya beli masyarakat akan 
Vol 1, No. 2 (2020), Desember 2020

E-ISSN: 2746-2471, DOI:

mempengaruhi kegiatan operasional usaha secara signifikan. Kedua hal ini dapat menjadi ancaman dan juga peluang bagi usahaKedai Susu Segar Wr. Agus.

\section{b. Legalitas}

Dalam aspek legalitas yang menjadi ancaman pada Kedai susu segar Wr. Agus belum memiliki SIUP (Surat Izin Usaha Perdagangan) karena pemilik Kedai susu segar Wr. Agus hanya izin usaha kepada warga setempat dan biasanya ada pelaku keamanan yang bertugas melindunginya.

\section{c. Sosial}

Hasil wawancara kepada pemilik Kedai susu segar Wr. Agus yang menyatakan bahwa ada beberapa hal yang mempengaruhi konsumen dalam pembelian pada Kedai susu segarWr. Agus yaitu yang pertama konsumen berpendapat bahwa minum susu setiap hari membuat tubuh menjadi sehat dan kandungan susu murni lebih banyak manfaatnya dibandingkan dengan produk susu lain yang diolah terlebih dahulu. Lalu yang kedua konsumen menyukai rasa susu murni yang disajikan pada Kedai susu segar Wr. Agus, biasanya konsumen baru yang membeli sering bertanya komposisi atau kemurnian dari susu tersebut.

\section{d. Teknologi}

Saat ini Usaha Kedai susu segar Wr. Agus ini kurang memanfaatkan kemajuan teknologi dan informasi saat sehingga daya saing pun mengalami ketidakstabilan seperti terlihat pada hasil analisis VRIO yang menunjukkan umumnya keunggulan kompetitif yang dimiliki baru pada keunggulan kompetitif seimbang dengan pesaing. Sebagai produk minuman sehat, usaha susu ini juga memiliki keunggulan kompetitif sementara yang harus selalu diperhatikan agar mampub ersaing.

\section{Analisis Pesaing}

Seperti terlihat pada tabel dibawah mengenai hasil analisis pesaing antara lain:

Tabel 2

Hasil Analisis Pesaing

\begin{tabular}{|c|c|c|c|c|c|}
\hline $\begin{array}{c}\text { No } \\
\text {. }\end{array}$ & Usaha & Tujuan & Asumsi & $\begin{array}{c}\text { Kemampuan } \\
\text { dan sumberdaya }\end{array}$ & Strategi \\
\hline 1. & $\begin{array}{l}\text { Kolam } \\
\text { susu }\end{array}$ & $\begin{array}{c}\text { Keuangan } \\
\text { Pangsa pasar } \\
\text { Struktur } \\
\text { organisasi } \\
\text { teknologi }\end{array}$ & $\begin{array}{l}\text { Pengalaman masa } \\
\text { lalu terhadap produk } \\
\text { Produk terpercaya } \\
\text { Trenter baru }\end{array}$ & $\begin{array}{l}\text { Pengalaman pemilik } \\
\text { pada bidang usaha } \\
\text { minuman } \\
\text { Baru mempunyai } 4 \\
\text { cabang } \\
8 \text { orang karywan } \\
\text { Fasilitas dine-in } \\
\text { Produk tidak hanya } \\
\text { minuman } \\
\text { Pengelolaan Medsos } \\
\text { Kombinasi buah segar }\end{array}$ & $\begin{array}{l}\text { Strategy } \\
\text { fokus }\end{array}$ \\
\hline
\end{tabular}


Vol 1, No. 2 (2020), Desember 2020

E-ISSN: 2746-2471, DOI:

\begin{tabular}{|c|c|c|c|c|c|c|c|}
\hline 2. Teguk & $\begin{array}{l}\text { a. } \\
\text { b. } \\
\text { c. } \\
\text { d. }\end{array}$ & $\begin{array}{l}\text { Keuangan } \\
\text { Pangsa } \\
\text { pasar } \\
\text { Strukturorg } \\
\text { anisasi } \\
\text { Teknologi }\end{array}$ & $\begin{array}{l}\text { c. } \\
\text { d. }\end{array}$ & $\begin{array}{l}\text { Pengalaman } \\
\text { masa lalu } \\
\text { terhadap } \\
\text { produk } \\
\text { Produk } \\
\text { terpercaya } \\
\text { Tren terbaru } \\
\text { Banyak } \\
\text { inovasi } \\
\text { minuman }\end{array}$ & $\begin{array}{l}\text { b. } \\
\text { c. } \\
\text { d. } \\
\text { e. }\end{array}$ & $\begin{array}{l}\text { Pengalaman } \\
\text { frenhcises produk } \\
\text { minuman } \\
\text { Tenaga kerja } \\
\text { professional } \\
\text { Mempunyai } 40 \\
\text { gerai di jabodetabek } \\
\pm 200 \text { karyawan } \\
\text { Manajemen } \\
\text { profesional }\end{array}$ & $\begin{array}{l}\text { Strategy } \\
\text { fokus }\end{array}$ \\
\hline
\end{tabular}

3. Thaitea a. Keuangan

b. Pangsa

Pasar

c. Struktur

organisasi

d. Teknologi a. Pengalaman

masa lalu terhadap produk

b. Produk

terpercaya a. Pengalaman pemilik pada bidang usaha minuman

b. 2 cabang

c. 2 orang karyawan
Strategy

Fokus 
Vol 1, No. 2 (2020), Desember 2020

E-ISSN: 2746-2471, DOI:

$\begin{array}{cccc}\text { September } & 1549 & 203 & 1752 \\ \text { Oktober } & 1402 & 144 & 1546 \\ \text { November } & 1146 & 210 & 1350 \\ \text { Desember } & 1023 & 111 & 1134 \\ \text { Januari* } & 1941 & 150 & 2091 \\ \text { Februari } & 1971 & 161 & 2132 \\ \text { Maret } & 1607 & 231 & 1838 \\ \text { April } & 1431 & 186 & 1617\end{array}$

*Cabang kedua mulai dibuka

Sumber : Manajemen Kedai Susu Segar Wr. Agus (2019-2020)

Tabel 4

Data Jumlah PenjualanJuni 2019-April 2020

\begin{tabular}{|c|c|c|c|}
\hline \multirow{2}{*}{ Bulan } & \multicolumn{2}{|c|}{ Produk (Per gelas) } & \multirow{2}{*}{$\begin{array}{c}\text { Pendapatan } \\
\text { Kotor }\end{array}$} \\
\hline & Rp. 10.000 & Rp. 12.000 & \\
\hline Juni & Rp.8.200.000 & Rp.720.000 & Rp. 9.080.000 \\
\hline Juli & Rp. 15.370 .000 & Rp.1.200.000 & Rp. 16.570 .000 \\
\hline Agustus & Rp.13.800.000 & Rp.4.200.000 & Rp. 18.000 .000 \\
\hline September & Rp. 15.490 .000 & Rp.2.436.000 & Rp. 17.926 .000 \\
\hline Oktober & Rp.14.020.000 & Rp.1.728.000 & Rp. 15.749 .000 \\
\hline November & Rp.11.460.000 & Rp.2.520.000 & Rp.13.980.000 \\
\hline Desember & Rp. 10.230 .000 & Rp.1.332.000 & Rp. 11.563 .000 \\
\hline Januari* & Rp. 15.852 .600 & Rp.1.624.400 & Rp.17.477.000 \\
\hline Februari & Rp.19.710.000 & Rp.1.932.000 & Rp.21.642.000 \\
\hline Maret & Rp.12.747.900 & Rp.2.473.200 & Rp. 15.220 .900 \\
\hline April & Rp. 11.819 .500 & Rp.1.822.200 & Rp.13.641.700 \\
\hline Total & Rp.148.750.000 & Rp.22.187.400 & Rp.170.937.400 \\
\hline
\end{tabular}

*Cabang 2 dibuka

Sumber : Manajemen Kedai Susu Segar Wr. Agus (2019-2020)

Berdasarkan data kuantitas dan penjualan dan data jumlah penjualan Kedai susu segar Wr. Agus dari bulan juni 2019 sampai dengan april 2020 mengalami penaikan dan penurunan baik dari jumlah kuantitas dan jumlah penjualan hal ini dikarenakan kedai susu pada awal juni baru membuka usahanya sehingga konsumen belum banyak yang membeli dan untuk bulan desember terjadi penurunan omset karena pengaruh cuaca yang membuat minat konsumen membeli minuman es susu berkurang. Secara jelas Total biaya variabel dan tetap yang digunakan pada kedai susu segarWr.Agus.

Tabel5.

Kedai susu segar Wr. Agus Cabang 1

Perhitungan Biaya Tetap Produk Bulan Juni 2019 - April 2020

\begin{tabular}{cccc}
\hline Bulan & $\begin{array}{c}\text { Jumlah Penjualan } \\
\text { (Per Gelas })\end{array}$ & $\begin{array}{c}\text { Biaya Tetap } \\
\text { Per porsi }\end{array}$ & Total Biaya Tetap \\
\hline Juni & 860 & Rp. 1.562 & Rp. 1.343 .320 \\
Juli & 1637 & Rp. 1.562 & Rp. 2.556 .994 \\
Agustus & 1730 & Rp. 1.562 & Rp. 2.702 .260 \\
September & 1752 & Rp. 1.562 & Rp. 2.736 .624 \\
Oktober & 1546 & Rp. 1.562 & Rp. 2.414.852 \\
November & 1356 & Rp. 1.562 & Rp. 2.118 .072 \\
Desember & 1134 & Rp. 1.562 & Rp. 1.771 .308
\end{tabular}


Vol 1, No. 2 (2020), Desember 2020

E-ISSN: 2746-2471, DOI:

\begin{tabular}{cccc} 
Januari & 1251 & Rp. 1.562 & Rp. 1.954.062 \\
Februari & 1165 & Rp. 1.562 & Rp. 1.819.730 \\
Maret & 1029 & Rp. 1.562 & Rp. 1.607.298 \\
April & 987 & Rp. 1.562 & Rp. 1.541.694 \\
\hline \multicolumn{4}{c}{ Sumber: Manajemen Kedai Susu Segar Wr. Agus (2019-2020) } \\
\multicolumn{4}{c}{ Tabel 6 } \\
\multicolumn{4}{c}{ Kedai susu segar Wr. Agus Cabang 2 } \\
\hline \multicolumn{4}{c}{ Perhitungan Biaya Tetap Produk } \\
Bulan & Bulan Januari - April 2020 \\
\hline Januari & Bumlah Penjualan & Biaya Tetap & Total Biaya Tetap \\
Februari & Per Gelas ) & Rp. 2.187 & Rp. 1.837.080 \\
Maret & 940 & Rp. 2.187 & Rp. 2.114.829 \\
April & 809 & Rp. 2.187 & Rp. 1.769.283 \\
\hline
\end{tabular}

Sumber: Manajemen Kedai Susu Segar Wr. Agus (2020)

Tabel 7.

Perhitungan Total Biaya

Kedai susu segar Wr. Agus cabang 2

Bulan Januari - April 2020

\begin{tabular}{cccc}
\hline Bulan & Biaya Variabel & Biaya Tetap & Total Biaya \\
\hline Januari & Rp.4.727.000 & Rp. 1.837 .080 & Rp.6.564.000 \\
Februari & Rp.5.411.600 & Rp. 2.114 .829 & Rp. 7.526 .000 \\
Maret & Rp.4.257.900 & Rp.1.769.283 & Rp.6.027.183 \\
April & Rp.3.109.500 & Rp. 1.397 .493 & Rp. 4.506.993
\end{tabular}

Sumber: Manajemen Kedai Susu Segar Wr. Agus 2020)

Tabel 8

Perhitungan Total Biaya

Kedai susu segar Wr. Agus Cabang 1

Bulan Juni 2019- April 2020

\begin{tabular}{cccc}
\hline Bulan & Biaya Variabel & Biaya Tetap & Total Biaya \\
\hline Juni & Rp. 4.935.300 & Rp. 1.343.320 & Rp. 6.278.620 \\
Juli & Rp. 8.944.500 & Rp. 2.556.994 & Rp. 11.501.494 \\
Agustus & Rp. 9.702.100 & Rp. 2.702.260 & Rp. 12.404.360 \\
September & Rp. 9.867.800 & Rp. 2.736.624 & Rp. 12.604.424 \\
Oktober & Rp. 8.369.000 & Rp. 2.414.852 & Rp. 10.783.852 \\
November & Rp. 7.729.000 & Rp. 2.118.072 & Rp. 9.847.072 \\
Desember & Rp. 6.578.600 & Rp. 1.771.308 & Rp. 8.349.908 \\
Januari & Rp. 7.134.600 & Rp. 1.954.062 & Rp. 9.088.662 \\
Februari & Rp. 6.595.000 & Rp. 1.819.730 & Rp. 8.414.730 \\
Maret & Rp. 6.122.500 & Rp. 1.607.298 & Rp. 7.729.798 \\
April & Rp. 5.612.600 & Rp. 1.541.694 & Rp. 7.154.249 \\
\hline Total Biaya & Rp. 81.591.000 & Rp. 22.566.214 & Rp. 104.157.214 \\
\hline Sumber: Manajemen Kedai Susu Segar Wr. Agus (2019-2020)
\end{tabular}

Tabel 9

Hubungan Biaya-Volume-Laba Kedai susu segar Wr. Agus bulan Juni 2019-April 2020

\begin{tabular}{cccc}
\hline $\begin{array}{c}\text { Produk } \\
(\text { Per Gelas })\end{array}$ & $\begin{array}{c}\text { Harga Jual } \\
(\mathrm{Rp})\end{array}$ & $\begin{array}{c}\text { Total Biaya } \\
(\mathrm{Rp})\end{array}$ & $\begin{array}{c}\text { Persentase Laba } \\
(\mathrm{Rp})\end{array}$ \\
\hline Original & 10.000 & 5.762 & $42.38 \%$
\end{tabular}




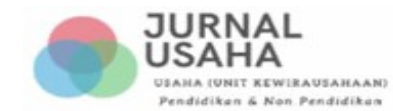

Vol 1, No. 2 (2020), Desember 2020

E-ISSN: 2746-2471, DOI:

\begin{tabular}{cccc} 
Coklat & 10.000 & 7.262 & $27,38 \%$ \\
Vanilla & 10.000 & 7.562 & $24,38 \%$ \\
Oreo & 10.000 & 7.262 & $27,38 \%$ \\
Taro & 10.000 & 7.262 & $27,38 \%$ \\
Pisang & 10.000 & 7.262 & $27,38 \%$ \\
Leci & 10.000 & 7.262 & $27,38 \%$ \\
Alpukat & 10.000 & 7.262 & $27,38 \%$ \\
Blueberry & 10.000 & 7.262 & $27,38 \%$ \\
Strawberry & 10.000 & 7.262 & $27,38 \%$ \\
Melon & 10.000 & 7.562 & $24,38 \%$ \\
Red velvet & 10.000 & 7.262 & $27,38 \%$ \\
Green tea & 10.000 & 7.262 & $27,38 \%$ \\
Durian & 10.000 & 7.262 & $27,38 \%$ \\
Milo & 12.000 & 7.762 & $42.38 \%$ \\
Ovaltine & 12.000 & 7.762 & $42.38 \%$ \\
Beng-beng & 12.000 & 7.762 & $42.38 \%$ \\
Moccacino & 12.000 & 7.562 & $44,38 \%$ \\
Capucino & 12.000 & 7.562 & $44,38 \%$ \\
Kacang hijau & 12.000 & 7.762 & $42,38 \%$ \\
\hline Sumber: Manajemen Kedai Susu Segar Wr. Agus $(2019-2020)$
\end{tabular}

Berdasarkan hasil perhitungan keuntungan antara harga jual per cup (harga non aplikasi) dengan biaya-biaya yang dikeluarkan diperoleh hubungan biayavolume-laba Kedai susu segar Wr. Agus. Hubungan biaya volume laba yang kuat memberi indikasi bagi pemilik dalam melakukan peningkatan biaya pemasaran atau potongan harga bila tindakan ini akan meningkatan penjualan, tetapi pada Kedai susu segar Wr. Agus meskipun semakin besar volume penjualan diperoleh persentase keuntungan yang semakin kecil, namun hal ini tidak menyebabkan kerugian bagi Kedai susu segar Wr. Agus. Hal ini dikarenakan berdasarkan data penjualan pada bulan Juni 2019 sampai dengan April 2020 sebagian besar konsumen membeli produk minuman susu yang memberikan keuntungan bagi pengelola Kedai susu segar Wr. Agus sebesar 20\% - 40\% per cup. Kebijakan harga yang dibuat oleh Kedai susu segar Wr. Agus memperhitungkan kuantitas produk yang dijual untuk setiap harganya.

\section{SIMPULAN}

Berdasarkan hasilpenelitian diketahuibahwaaktivitas dan strategi pemasaran yang diterapkan Kedai susu segar Wr. Agus sudah efektif untuk Cabang 1 tetapi belum efektifuntukCabang 2 karena hasilpenjualan masih belum bisa membuat usaha ini mencapai skala ekonomis.Adapun saran yang diberikanadalah pemiliki harus menentukan merek agar dapat dikenal dan diingat oleh masyarakat, penentuan target penjualan harus dihitung berdasarkan BEP dan Skala Ekonomis sehingga usaha dapat berkembang, penyediaan fasilitas untuk drink in, agar konsumen dapat tertarik untuk berkunjung karena disediakan sarana tersebut dan memanfaatkan media social seperti Instragram, Twitter dan juga Facebooksebagai media komunikasi dan informasisetiapproduk dan program pemasaran yang dilakukan. 
Vol 1, No. 2 (2020), Desember 2020

E-ISSN: 2746-2471, DOI:

\section{DAFTAR PUSTAKA}

Arif, M. Z. U. (2016). Using the 7Ps of Booms and Bitner as Controllable Tactical Marketing Tools: An Exploratory Study on Selected Super Shops in Bangladesh. International Journal of Trade and Commerce-IIARTC, 5(1), $12-29$.

Assauri, S. (2018). Manajemen Pemasaran: Dasar, Konsep \& Strategi. Jakarta: Rajawali Press.

Barney, J. (1991). Firm resources and sustained competitive advantage. Journal of Management, 17(1), 99-120.

Cravens, D., \& Piercy, N. (2012). Strategic Marketing (10th ed.). New York: McGraw-Hil Educcation.

Khoerunisa, A. (2019). Strategi Pemasaran Produk Dalam Meningkatkan Volume Penjualan Batik Putri Ayu Desa Limbasari Kecamatan Bobotsari, Kabupaten Purbalingga. IAIN Purwokerto.

Kotler, P., \& Armstrong, G. (2017). Principles of Marketing, Global Edition (Vol. 17th). Pearson.

Kotler, P., \& Keller, K. L. (2016). Marketing management (15th global ed.). England: Pearson.

Kusumawaty, Y. (2018). Strategi pemasaran produk makanan ringan khas Riau (keripik nenas dan rengginang ubi kayu). Jurnal Agribisnis, 20(2), 124-138.

Pertiwi, N. A. (2019). STRATEGI PEMASARAN HYDRO COCO DENGAN ANALISIS SWOT PADA PT. ENSEVAL PUTERA MEGATRADING TBK CABANG BANJARMASIN. Jurnal Ilmiah Ekonomi Bisnis, 5(2).

Porter, M. E. (1980). Competitive strategy: Techniques for analyzing industries and competitors. Editorial Free Press.

Tjiptono, F., \& Chandra, G. (2017). Pemasaran strategik. Yogyakarta: Andi (Edisi 2). Yogyakarta: Andi Offset.

Widati, E. (2012). Resolving the strategy paradox applying the strategic flexibility: A case study of PT BNI life insurance. International Research Journal of Business Studies, 5(2).

Wirtz, J., \& Lovelock, C. (2016). Services marketing: People, technology. World Scientific Publishing Company. 